\title{
Assessment of Dental Undergraduate Students' Skills in Local Anesthesia Administration: A Longitudinal Study
}

\author{
Siddiqi, K.M. ${ }^{1}$, Qazi, H.S. ${ }^{1}$, Ali, K. ${ }^{1,2}$ \& Glanville, . $^{3}$
}

\begin{abstract}
Objectives: To investigate the quantitative impact of experience on competence in local anesthetic administration amongst final-year Bachelor of Dental Surgery (BDS) students.

Methods: A Longitudinal cohort study design was employed. Purposive sampling was used to enrol final year BDS students and assess their competence longitudinally over a full academic year. The assessment criteria and scoring structure were reviewed during inspection of the institution by the regulator and the external examiner. Participants were assessed on four occasions, namely, after they had gained experience in performing 15, 40, 70 and 100 patient encounters involving local anesthetic administration.
\end{abstract}

Results: A total of 177 participants who were assessed including 31 males (18\%) and 146 females (82\%). Assessment of the participants on four occasions provided a total of 885 data points. A chi-square test was carried out to test the hypothesis. Students in Group 4 with over 100 patient encounters were most likely to pass assessment, while students in 1 with 15 patient encounters were most likely to fail. There was a statistically significant variation in the proportion of 'Below Standard', 'Meets Standard' and 'Exceeds Standard' judgements awarded to students with differing levels of prior experience $(p<0.001)$, confirming the research hypothesis. Data on differential performance of students by gender did not show significant differences.

Conclusions: The results of this study show a linear relationship between the number of patient encounters involving administration of local anesthesia and demonstration of competency amongst final year dental students. Over $90 \%$ students achieved competence after performing 100 patient encounters.

Keywords: Competence, dental students, local anesthesia, undergraduate

\section{Introduction}

Safe and effective administration of local anesthesia (LA) is a fundamental skill in undergraduate dental education (Knipfer et al, 2018; ADA Guidance for the use of sedation and general anaesthesia by dentist, 2020).

${ }^{1}$ Dental Section, Islamabad Medical \& Dental College, Islamabad, Pakistan.

${ }^{2}$ Faculty of Health (Medicine, Dentistry and Human Sciences), University of Plymouth, United Kingdom

${ }^{3}$ Peninsula Dental School, University of Plymouth United Kingdom

Corresponding Author: Dr. Khalid Mahmood Siddiqi Professor and Head, Oral \& Maxillofacial Surgery Department, Dental Section, Islamabad Medical \& Dental College, Islamabad, Pakistan.

Email: khalid.siddiqi@iideas.edu.pkDOI:

http://doi.org/10.4038/seajme.v14i2.223
Dental treatment is often associated with stress, anxiety, and phobia, which are often attributed to pain (expected and actual) associated with dental injections (Crawford et $a l, 2005)$. The pain can lead to a fear of dentists and avoidance of further treatment which can put patients at risk of developing dental infections, which in extreme cases can lead to sepsis and may warrant admission to hospital. Clinically significant fear of dental injections may be seen in $25 \%$ adults and one in 20 patients may avoid dental treatment because of a fear of dental injections (Milgrom et al, 1997). Dental professionals' skills in administration are contribute significantly to enhancing patient confidence (Premnath, 2020).

Historically, the practise of LA was started in 1884 by Halsted and Hall, with injection of a cocaine solution into mandibular foramen region (Matas, 1952). Since then, LA has 
become an integral part of contemporary dentistry with an overarching aim to provide pain-free and effective dental treatment to patients (Hysi et al, 2018).

A variety of teaching and learning methods are utilised in dental education to impart the knowledge and skills required for safe and effective administration of LA to patients. The knowledge underpinning the practise of LA is usually delivered using didactic teaching. However, practical teaching on LA varies amongst dental institutions especially in regard to training in simulated dental learning environment and in many institutions dental students usually administer their first injection on their peers (Brand et al, 2010). It has been reported that dental students often find learning LA skills on peers is associated great anxiety and stress for both the "recipient" and the "operator". Another common approach to impart clinical training of dental students in LA skills involves observation followed by attempt (i.e. "see one, do one, teach one") (Udani et al, 2015).

Acquisition of competence in clinical skills requires structured teaching and adequate exposure to patients providing students opportunities to consolidate their clinical skills. There is a dearth of published literature regarding the minimum clinical targets required by dental students to develop and consolidate their skills in safe and effective administration of local anaesthesia. Given the variations in regional anatomy, pain thresholds and cooperation levels in individual patients, it is important to assess the competence of dental students on multiple occasions. This would allow dental educators to assess the ability of the student to adapt to variations in patients and also identify learning needs of individual students. Therefore, the relationship between experience in LA administration and competence assessment of dental students warrants further investigation.

The aim of the study was to determine the value of the number of patient encounters for LA administration on the competence of undergraduate students.

\section{Methods}

\section{Research hypothesis}

The research was based on the hypothesis that competence in administration of LA correlates with the number of patient encounters.

Study design
A longitudinal cohort study design was employed for this study.

\section{Participants and settings}

Purposive sampling targeting final year BDS students was used at IMDC. The participants were assessed longitudinally over a full academic year.

\section{Assessment methodology}

Participants were assessed on four occasions i.e., after 15, 40, 70 and 100 patient encounters involving administration of local anesthesia to achieve pain control for tooth extractions.

Assessment was based on four subcomponents and Students performance for each of the sub-components was graded as: Exceeds standard (ES); Meets standard (MS); or Below standard (BS). The assessment criteria and scoring structure were validated by the external examiner and are provided in the appendix.

\section{Data Collection}

Assessment data for each participant was recorded on purposefully designed pro forma and transferred to Microsoft Excel by a designated administrator. If a participant multiple local anesthetic injection in a single patient encounter, the lowest performance was used to grade competence. Accuracy of the data was checked by two staff members of the faculty.

\section{Data Analysis}

Data was analysed using RStudio (version 1.3.959) incorporating $R$ version 4.0.2 (RStudio Team, 2020). Chi-squared tests of independence were carried out for each assessment component and experience group. Chi-squared tests are subject to potential problems caused by zero or near-zero cell counts. To circumvent such problems all $p$ values were estimated by Monte Carlo simulation with $1,000,000$ replicates.

\section{Research Ethics}

Ethics approval was granted by the institutional review board (IRB) vide letter no. IMDC/DS/IRB/164 dated December 19, 2018.

\section{Results}

There were 177 who were assessed for competency in LA administration including 31 males (18\%) and 146 females (82\%). The age range of participants was 22 to 24 years 
(mean=21.92; median=22). The total number of assessment data points available for the four assessments were 885 as shown in Table 1.

Table 1: Judgement Distribution for Local Anesthesia Competency

\begin{tabular}{cccccccc}
\hline Group & $\begin{array}{c}\text { Judgements } \\
(\mathrm{N})\end{array}$ & $\begin{array}{c}\text { Exceeds } \\
\text { Standard }\end{array}$ & $\begin{array}{c}\text { Exceeds } \\
\text { Standard } \\
\text { (prop) }\end{array}$ & $\begin{array}{c}\text { Meets } \\
\text { Standard }\end{array}$ & $\begin{array}{c}\text { Meets } \\
\text { Standard } \\
\text { (prop) }\end{array}$ & $\begin{array}{c}\text { Below } \\
\text { Standard }\end{array}$ & $\begin{array}{c}\text { Below } \\
\text { Standard } \\
\text { (prop) }\end{array}$ \\
\hline 15 & 235 & 1 & 0.00 & 183 & 0.78 & 51 & 0.22 \\
40 & 220 & 5 & 0.02 & 184 & 0.84 & 30 & 0.14 \\
70 & 215 & 8 & 0.04 & 184 & 0.86 & 23 & 0.11 \\
100 & 215 & 12 & 0.06 & 186 & 0.87 & 17 & 0.08 \\
All & 885 & 26 & 0.03 & 737 & 0.83 & 121 & 0.14 \\
\hline
\end{tabular}

A graphical representation of assessment results after 15, 40, 70 and 100 patient encounters are depicted in Figure 1.

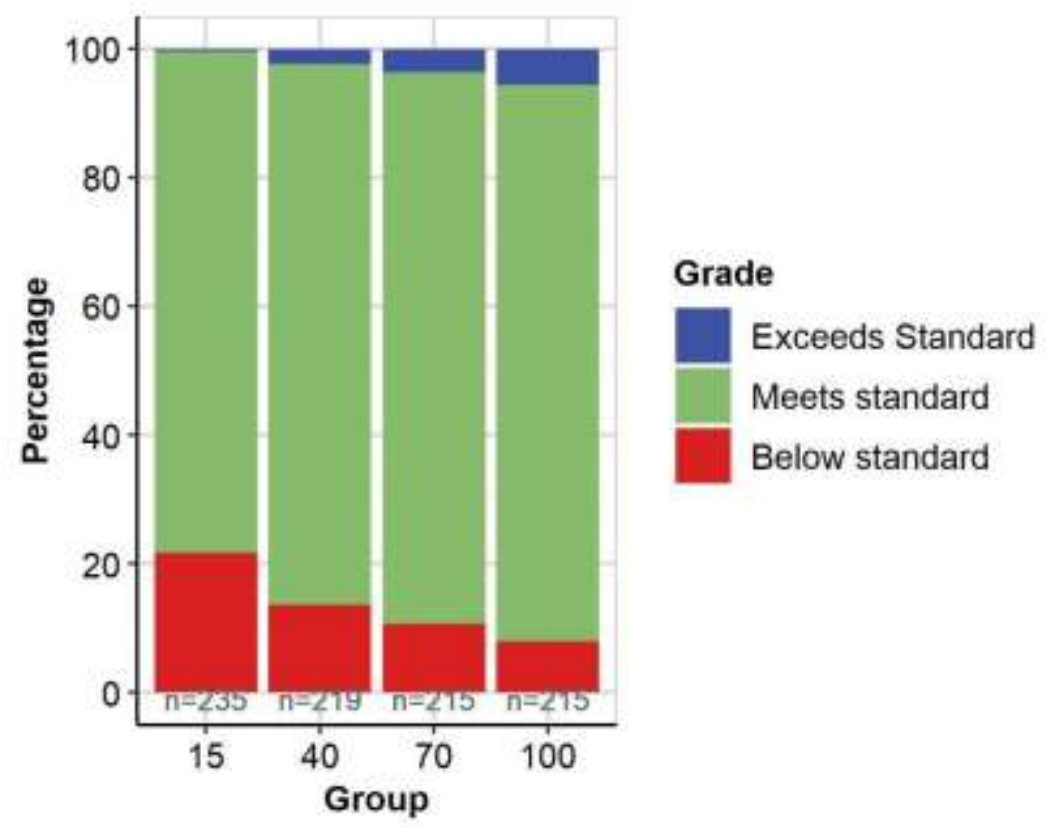

\section{Figure 1: Distribution of judgements of local anesthesia assessments}

Chi-Squared Analysis

A chi-square test was carried out of the hypothesis that competence in LA skill increases with increasing exposure to patients. The $p$-value of $<0.001$ indicated that there is statistically significant variation in the proportion of 'Below Standard', 'Meets
Standard' and 'Exceeds Standard' judgements awarded to students with differing levels of prior experience which justifies acceptance of the hypothesis.

The level of variation across each cohort group and the sub-component assessments judgements awarded were calculated using the 
chi-square residual values. Positive residuals indicate that the group was more likely to achieve that particular judgement than would be expected if there were no relationship between group and judgement awarded. It can be seen that, when judgements across all subcomponents in LA competency are considered, students in Group 15 were more likely to receive a judgement of 'Below Standard' and Group 100 were more likely to receive a judgement of 'Exceeds Standard'. The results chi square calculations of residual values are depicted in Table 2.

Table 2: Chi-square analysis residual values (all sub-components)

\begin{tabular}{cccc}
\hline Group & Exceeds Standard & Meets Standard & Below Standard \\
\hline 15 & -2.249 & -0.923 & 3.321 \\
40 & -0.568 & 0.105 & 0.004 \\
70 & 0.667 & 0.355 & -1.185 \\
100 & 2.257 & 0.504 & -2.291 \\
\hline
\end{tabular}

Students with a 'Below Standard' judgement in more than one sub-components were deemed to have failed the assessment. Table 3 provides a breakdown of the component grades by cohort (number and proportion of grades awarded).

Table 3: Grade distribution of participants

\begin{tabular}{cccccc}
\hline Group & Judgements & Pass & Pass (prop) & Fail & Fail (prop) \\
\hline 15 & 47 & 34 & 0.72 & 13 & 0.28 \\
\hline 40 & 44 & 36 & 0.82 & 8 & 0.18 \\
\hline 70 & 43 & 38 & 0.88 & 5 & 0.12 \\
\hline 100 & 43 & 39 & 0.91 & 4 & 0.09 \\
\hline All & 177 & 147 & 0.83 & 30 & 0.17 \\
\hline
\end{tabular}

A chi-square test was carried out of the hypothesis that competence in LA skills increases with increasing exposure to patients. As shown in Table 4, the p-value of 0.001 indicates that there is statistically significant variation in the proportion of 'Pass' and 'Fail' grades awarded to students with differing levels of prior experience and so the hypothesis can be accepted.

Analysis for differential performance of students by gender did not show significant differences between males and females $(p>0.05)$.

Table 4: Chi-square analysis (overall grade)

\begin{tabular}{ccccc}
\hline Factor & $\begin{array}{c}\text { Degrees of } \\
\text { Freedom }\end{array}$ & Sample size & Chi-Square value & p-value \\
\hline Group & 3 & 221 & 6.529 & 0.088 \\
\hline
\end{tabular}




\section{Discussion}

This is perhaps the first study to report longitudinal assessment of competency in LA administration in an undergraduate dental program. We have a four-year Bachelor of Dental Surgery (BDS) program at our institution and the teaching on LA commences in the prefinal year and students get clinical exposure shadowing final year students. The students get to practise their skills in LA in the final year in conjunction with a variety of clinical procedures including tooth extractions under supervision of faculty staff.

There is a considerable variation regarding the stage at which LA teaching is introduced in undergraduate dental curricula. Traditional dental curricula often teach basic sciences in the first two years and clinical disciplines are only introduced in the subsequent years. However, evidence from the literature suggests that early clinical exposure may offer greater opportunities not only to develop their clinical skills but also skills in communication, professionalism and team working (Ali et al, 2018).

There is a growing trend to provide clinical patient exposure at an early stage in many dental programs. However, patient safety is a primary concern and institutions must ensure that students receive appropriate pre-clinical training in simulated settings and are also assessed summatively before undertaking clinical procedures on patients. Although local anesthetic administration is a core skill, it can be associated with a variety of complications. Systemic complications such as vasovagal fainting, precipitation of acute chest pain, asthma, epileptic fits may be observed during dental injections due to anxiety and needle phobia (Malamed, 2020). Similarly, local complications such as soft tissue damage, needle breakage, nerve damage and trismus may complicate dental injections (MontserratBosch et al, 2014).

It is widely reported in the literature that undergraduate students may not feel confident in administering their first few injections on patients (Brand et al, 2011). Simulated dental learning environments provide low-risk settings for teaching practical skills to dental students including administration of local anesthesia. Although our students do not get local anesthetic teaching on mannequins, evidence from the literature shows that this may serve to enhance student confidence. Unsurprisingly, the last decade has witnessed a growing trend of teaching dental skills in a simulated environment in European dental schools (Udani et al, 2015; Brand et al, 2011; Stelzle et al, 2011).

The assessments of the participants in this study were carried out the entire academic year. Assessors included five members of the faculty with a minimum of three years' experience in undergraduate teaching. Calibration of the assessors was carried out by the lead assessor using assessment results and written feedback from 10 students of a previous cohort. Each assessor marked the performance individually and the scores were shared by the group. The assessors deliberated on the justification of their individual scores to achieve a consensus on application of assessment criteria to score student performance. The assessor calibration was undertaken prior to commencement of the study and repeated after 4 months. Each student was assessed by a single assessor.

The assessments were scheduled for individual students following their achievement of clinical targets for each of the four assessments i.e., after 15, 40, 70 and 100 patient encounters. A criterion-referenced assessment criteria was used to measure LA competence (Turnbull, 1989). External validity of the assessment was furnished through review of the assessment criteria by institutional subject experts as well as the external examiner (Hamdy et al, 2003). On reflection, it was felt that improvements in calibration could be achieved by assessing live performance of candidates and we are considering a variety of options for future calibration including: (a) live assessment of students working in routine clinics as a group of assessors; (b) developing a bank of videorecorded performances by students undertaking extractions (Sturman et al 2018).

Although our results show a linear relationship between competence in LA administration and experience of the participants, interpretation of the results warrants a degree of caution. The sample was based on a single cohort of students from institution. Teaching of dental students using a competency-based framework is appropriate. However, the number of times a student carries out a specific clinical procedure is not always a reliable predictor of competency (Wimmers et al, 2006). Performance assessment of students under different contexts (breadth) may be a more reliable method to assess their competence (Dawson et al, 2017). The process of developing the capacity for independent practice typically extends well beyond the temporal confines of undergraduate university education and a new 
dental graduate may take several years to consolidate their skills (Ali et al, 2014). Nevertheless, it is acknowledged that curriculum design, teaching strategy and logistics at individual institutions may ultimately inform the training model and competence assessments of students.

\section{Conclusion}

The results of this study show a positive relationship between the number of patient's exposures involving LA administration and competence of final year dental students. After 100 patient encounters, over 90\% students were assessed to be competent. However, a linear relationship with experience of the students, as observed in this study, and caution is required before drawing any generalisations. Given the limitations of sample size from a single institution, further research is required to investigate the value of increased experience on student competence.

\section{Conflict of Interest}

The authors have no conflict of interest to declare

\section{Acknowledgements}

The authors would like to thank all staff and students who participated in this study.

\section{References}

Ali, K., Tredwin, C., Kay, E.J., Slade, A. and Pooler, J. (2014). Preparedness of dental graduates for foundation training: a qualitative study. Br Dent J, 217(3), pp.145149.

Ali, K., Zahra, D., McColl, E., Salih, V. and Tredwin, C. (2018). Impact of early clinical exposure on the learning experience of undergraduate dental students. Eur J Dent Educ, 22(1), pp. e75-e80.

American Dental Association (2020). Guidance for the use of sedation and general anaesthesia by dentist. Available online at: http://www.ada.org/ /media/ADA/Education $\% 20$ and\%20Careers/Files/anesthesia_use _guidelines.pdf (Accessed October 2020)

Brand, H.S., Baart, J.A., Maas, N.E. and Bachet, I. (2010). Effect of a training model in local anesthesia teaching. J dent edu, 74(8), pp.876-879.
Brand, H.S., Tan, L.L.S., Van Der Spek, S.J. and Baart, J.A. (2011). European dental students' opinions on their local anaesthesia education. Eur J Den Educ, 15(1), pp.47-52.

Crawford, S., Niessen, L., Wong, S. and Dowling, E. (2005). Quantification of patient fears regarding dental injections and patient perceptions of a local noninjectable anesthetic gel. Compend Contin Educ Dent, 26(2 Suppl 1), p.11-4.

Dawson, L.J., Mason, B.G., Bissell, V. and Youngson, C. (2017). Calling for a reevaluation of the data required to credibly demonstrate a dental student is safe and ready to practice. Eur J Dent Educ, 21(2), p.130.

Hamdy, H., Prasad, K., Williams, R. and Salih, F.A. (2003). Reliability and validity of the direct observation clinical encounter examination (DOCEE). Med Ed, 37(3), pp.205-212.

Hysi, D., Caglar, E., Droboniku, E., Toti, C., Petro, E. and Kuscu, O. (2018). Role of "Video Assisted Lecture" on changing Albanian undergraduate students' opinion regarding pain-free dental injections in children. Acta Stomatologica Croatica, 52(3), pp.238-245.

Knipfer, C., Rohde, M., Oetter, N., Muench, T., Kesting, M.R. and Stelzle, F. (2018). Local anaesthesia training for undergraduate students-how big is the step from model to man?. BMC Med Educ, 18(1), pp.1-8. https://doi.org/10.1186/s12909-018-1389-6

Malamed, S.F. Handbook of Local Anesthesia. 6th Ed. (2020). St. Louis, Missouri, Elsevier. $13 ; 202$.

Matas, R. (1952). The story of the discovery of dental anesthesia by nerve blocking: achievements of William Stewart Halsted. Surgery, 32(3), pp.530-537.

Milgrom, P., Coldwell, S.E., Getz, T., Weinstein, P. and Ramsay, D.S. (1997). Four dimensions of fear of dental injections. J Am Dent Assoc, 128(6), pp.756-766.

Montserrat-Bosch, M., Figueiredo, R., Nogueira-Magalhães, P., ArnabatDominguez, J., Valmaseda-Castellón, E. and Gay-Escoda, C. (2014). Efficacy and complications associated with a modified inferior alveolar nerve block technique. A 
randomized, triple-blind clinical trial. Med Oral Patol Oral Cir Bucal, 19(4), p.e391-397.

Premnath, S., Alalshaikh, G., Alfotawi, R. and Philip, M. (2020). The association between coffee consumption and local anesthesia failure: social beliefs and scientific evidence. Cureus, 12(4). DOI 10.7759/cureus.7820

RStudio Team (2020). RStudio: Integrated Development Environment for R. Studio, PBC, Boston, MA. http://www.rstudio.com/ (Accessed August 2020).

Stelzle, F., Farhoumand, D., Neukam, F.W. and Nkenke, E. (2011). Implementation and validation of an extraction course using mannequin models for undergraduate dental students. Acta Odont Scand, 69(2), pp.8087.
Sturman, N., Wong, W.Y., Turner, J. and Allan, C. (2018). Online examiner calibration across specialties. The Clin Teach, 15(5), pp.377-381.

Turnbull, J.M. (1989). What is... normative versus criterion-referenced assessment. Med Teach, 11(2), pp.145-150.

Udani, A.D., Kim, T.E., Howard, S.K. and Mariano, E.R. (2015). Simulation in teaching regional anesthesia: current perspectives. Local and regional anesthesia, 8, p.33.

Wimmers, P.F., Schmidt, H.G. and Splinter, T.A. (2006). Influence of clerkship experiences on clinical competence. Med Educ, 40(5), pp.450-458. 


\section{Appendix-I}

Assessment Criteria for Local Anesthesia Competency

\section{Component}

\section{Technique of administration}

a. Patient /operator position

b. Correct assembly of LA syringe / cartridge

c. Recognition of anatomical landmarks

d. Delivery of local anesthetic

\section{Safe use of local anesthetic equipment}

a. Secures needle after injection appropriately

b. Safe disposal of anesthetic needle and cartridge after use

3. Confirmation of effectiveness of local anesthesia

a. Confirms effectiveness with the patient verbally

b. Confirms effectiveness objectively with light touch, deep pressure and pin-prick sensation

4. Remedial measures to manage ineffective local anesthesia

a. Reassures the patient

b. Repeat injections appropriately

\section{Exceeds Standard}

Correct technique, free of errors

or

Correct storage and disposal of LA equipment; no errors

$\begin{array}{lcc}\text { Confirms } & \text { effectiveness of } \\ \text { anesthesia verbally as well as } \\ \text { objectively } \\ \text { using appropriate }\end{array}$

of

\section{as 1}

Confirms effectiveness of anesthesia verbally as well as objectively; minor inconsistencies

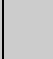

Safe storage and disposal of LA equipment; one minor error, corrected on a single prompt

Safe technique with no more than one minor error, corrected on a single prompt

Below Standard

ore than one error related to the four sub-components

Or

Single error not corrected on prompting

Multiple errors

Or

Single error not corrected on prompting

Does not confirm effectiveness of anesthesia

Confirms verbally objectively but not both repeat injection(s) appropriately OR manner with minor inconsistencies

of repeat

injection 